\title{
Screening for ecotoxicological effects of antiepileptic drugs in biologically treated waste water originating from an epilepsy ward by Danio rerio embryos
}

Christoph Hartwig $^{1 *}$, Elke Muth-Köhne ${ }^{2}$ and Rolf-Alexander Düring ${ }^{1}$

\begin{abstract}
Background: Pharmaceuticals, like antiepileptic drugs, are found regularly in surface waters, and consequently, advanced waste water treatment technologies are discussed for substance elimination. Because antiepileptic drugs have shown to transform to more toxic substances, their behavior in these treatment processes and resulting effects on ecotoxicity should be investigated. To validate if waste water from an epilepsy ward of a neurological hospital is appropriate for these investigations, it was treated with a membrane bioreactor (MBR), analyzed for antiepileptic drugs and screened for ecotoxicological effects with Danio rerio embryos. Further, the behavior of antiepileptic drugs in MBR treatment was estimated.
\end{abstract}

Results: Treatment of raw hospital waste water by the pilot scale MBR was successful regarding the low dissolved organic carbon concentration in the effluent and allowed ecotoxicological testing with $D$. rerio. According to the estimated behavior, partial elimination of 10-hydroxy-10,11-dihydrocarbamazepine (10-OH carbamazepine) and rufinamide and some release of lamotrigine, oxcarbazepine and, possibly, primidone occurred. The other investigated substances did not considerably change concentrations due to treatment. The highest concentrated substances found were 10-OH carbamazepine, lamotrigine, and oxcarbazepine. The complex mixture of the treated waste water had no effect on D. rerio morphology and did not change its primary and secondary motor neurons (indicator for developmental neurotoxicity). Oxcarbazepine did not show morphological effects on D. rerio at $8.7 \mathrm{mg} \mathrm{L}^{-1}$.

Conclusions: Biological treatment was not sufficient to significantly eliminate the load of antiepileptic drugs investigated. No effects on D. rerio embryos were observed. Biologically treated waste water, originating from an epilepsy ward, is appropriate for the investigation of the fate of antiepileptic drugs in advanced treatment processes.

Keywords: Oxcarbazepine; MBR; Membrane bioreactor; Hospital; Fish; Motor neurons; LC-TOF-MS

\footnotetext{
* Correspondence: christoph.hartwig@umwelt.uni-giessen.de

'Institute of Soil Science and Soil Conservation and Research Centre for BioSystems, Land Use and Nutrition (IFZ), Heinrich-Buff-Ring 26-32, Giessen 35392, Germany

Full list of author information is available at the end of the article
} 


\section{Background}

The first findings of pharmaceuticals, an important group of anthropogenic compounds, in the environment occurred in the 1970s (e.g., by Garrison et al. [1] and Hignite et al. [2]). Since then, pharmacologically active compounds were reported in numerous studies investigating rivers and lakes, as well as ground and drinking water.

Pharmaceuticals are excreted after administration in metabolized and unmetabolized forms, and subsequently reach waste water treatment plants (WWTPs) via sewer networks. Many pharmaceuticals are not sufficiently eliminated in WWTPs; thus, they reach receiving waters. Exemplary, concentrations of pharmaceuticals found in WWTP effluents and rivers are compiled in Table 1.

In order to assess the possible effects of substances on organisms, different ecotoxicological test systems are used; test systems for aquatic organisms include bacteria, algae, crustacean, and fish. Effect concentrations below $1,000 \mu \mathrm{g} \mathrm{L}^{-1}$ for pharmaceuticals found in WWTP effluents and rivers (Table 1) are given in Table 2. Effect concentrations found in ecotoxicological tests are in the range of environmental concentrations for the substance groups such as lipid regulators (bezafibrate), antiphlogistics (diclofenac), betablockers (metoprolol), and antiepileptic drugs (carbamazepine).

Due to numerous data on pharmacologically active compounds in the environment and the rising concern about possible chronic effects on aquatic organisms, treatment processes for elimination of these compounds were investigated. To improve elimination rates in WWTPs, not only the influence of sludge age and dosing of activated charcoal but also advanced treatment processes like ozonation, chlorination, UV-radiation, and combinations such as ozone/UV and $\mathrm{H}_{2} \mathrm{O}_{2} / \mathrm{UV}$ were investigated and discussed (e.g., [18-20]). Because oxidation processes can lead to the formation of toxic degradation products, possible effects of advanced treatment processes were investigated (e.g., by [21-23]).

The formation of toxic degradation products in advanced treatment processes was shown for the antiepileptic drugs carbamazepine and oxcarbazepine (e.g., by [24-27]). In [26], the authors found an elevation of acute toxicity on Daphnia magna due to UV treatment of oxcarbazepine, as they presumed, due to the formation of acridine. In [27], the authors found similar results for UV treatment of carbamazepine.

The prevalence of epilepsy is estimated at $0.91 \%$, and antiepileptic drugs were used by 634,566 patients in Germany in 2009 according to [28]. Since most epilepsy patients are in ambulant treatment, antiepileptic drugs can be detected in most, if not all, WWTP effluents, though data do not exist for all antiepileptic drugs. Hence, chemical transformations of antiepileptic drugs, which will occur if advanced treatment processes are
Table 1 Maximum concentrations of pharmaceuticals in municipal WWTP effluents and rivers

\begin{tabular}{|c|c|c|}
\hline Analyte & $\begin{array}{l}\text { Concentration at WWTP } \\
\text { effluents }\left(\mu \mathrm{g} \mathrm{L}^{-1}\right)\end{array}$ & $\begin{array}{l}\text { Concentration in rivers } \\
\text { and streams }\left(\mu \mathrm{g} \mathrm{L}^{-1}\right)\end{array}$ \\
\hline \multicolumn{3}{|l|}{ Lipid regulators } \\
\hline Bezafibrate & $4.6[3]$ & $3.1[3]$ \\
\hline Gemfibrozil & $1.5[3]$ & $0.51[3]$ \\
\hline \multicolumn{3}{|c|}{ Metabolites of lipid regulators } \\
\hline Clofibric acid & $1.6[3]$ & $0.55[3]$ \\
\hline Fenofibric acid & $1.2[3]$ & $0.28[3]$ \\
\hline \multicolumn{3}{|l|}{ Antiphlogistics } \\
\hline \multirow[t]{2}{*}{ Diclofenac } & $2.1[3]$ & $1.2[3]$ \\
\hline & $1.76[4]$ & \\
\hline $\begin{array}{l}\text { Acetylsalicylic } \\
\text { acid }\end{array}$ & $12.1[4]$ & \\
\hline Ibuprofen & $3.4[3]$ & $0.53[3]$ \\
\hline Acetaminophen & $6.0[3]$ & n.d. [3] \\
\hline Mefenamic acid & $1.36[4]$ & \\
\hline Paracetamol & $24.5[5]$ & $1.5[5]$ \\
\hline Tramadol & $97.6[5]$ & $5.97[5]$ \\
\hline \multicolumn{3}{|c|}{ Metabolites of antiphlogistics } \\
\hline Salicylic acid & $0.14[3]$ & $4.1[3]$ \\
\hline Gentisic acid & $0.59[3]$ & $1.2[3]$ \\
\hline \multicolumn{3}{|l|}{ Betablockers } \\
\hline Metoprolol & $2.2[3]$ & $2.2[3]$ \\
\hline Bisoprolol & $0.37[3]$ & $2.9[3]$ \\
\hline \multicolumn{3}{|l|}{ Stimulant } \\
\hline Caffeine & $3.18[4]$ & \\
\hline \multicolumn{3}{|l|}{ Antibiotics } \\
\hline Lincomycin & $45.7[4]$ & \\
\hline Sulfathiazole & $2.77[4]$ & \\
\hline Trimethoprim & $2.0[4]$ & \\
\hline Ciprofloxacin & $2.05[4]$ & \\
\hline \multicolumn{3}{|c|}{$\mathrm{H}_{2}$ receptor antagonist } \\
\hline Cimetidine & $9.4[5]$ & $0.2[5]$ \\
\hline \multicolumn{3}{|c|}{ Antiepileptic drugs } \\
\hline Gabapentin & $42.6[5]$ & $1.9[5]$ \\
\hline \multirow[t]{3}{*}{ Carbamazepine } & $6.3[3]$ & $1.1[3]$ \\
\hline & $21.6[4]$ & $0.3[5]$ \\
\hline & $4.6[5]$ & \\
\hline
\end{tabular}

n.d., no data; WWTP, waste water treatment plant. Data were taken from the reviews and screenings [3,6-8]. Empty fields: concentrations are not given in [3,6-8].

used, will probably influence the toxicity of waste water. To assess this possible influence, an investigation and treatment of waste water loaded with antiepileptic drugs and corresponding metabolites should be done. The 
Table 2 Toxicological data for substances of Table 1 with effect concentrations below $1,000 \mu \mathrm{g} \mathrm{L}^{-1}$

\begin{tabular}{|c|c|c|c|c|}
\hline Test & Species & Endpoint (time) & Endpoint & Effect concentration $\left(\mu \mathrm{g} \mathrm{L}^{-1}\right)$ \\
\hline \multicolumn{5}{|l|}{ Bezafibrate } \\
\hline Mussels & D. polymorpha & LOEC (7 days) & piGST transcript expression & $0.236[9]$ \\
\hline \multicolumn{5}{|l|}{ Diclofenac } \\
\hline Fish (adult) & O. mykiss & LOEC (28 days) & Cytophathology of the liver, kidney, and gills & $1[10]$ \\
\hline \multicolumn{5}{|l|}{ Metoprolol } \\
\hline Fish (adult) & O. mykiss & LOEC (28 days) & Cytopathology of the liver & $1[11]$ \\
\hline \multicolumn{5}{|l|}{ Carbamazepine } \\
\hline Rotoxkit (rotifers) & B. calyciflorus & LOEC (48 h) & Reproduction & $754[12]$ \\
\hline Phytoplankton & S. obliquus & $\mathrm{EC}_{50}$ (30 days) & Chlorophyll a synthesis & $800[13]$ \\
\hline \multirow[t]{2}{*}{ Crustaceans } & G. pulex & LOEC (1.5 h) & Behavior & 0.01 (ns) [14] \\
\hline & C. dubia & LOEC (7 days) & Reproduction & $100[12]$ \\
\hline Mussels & M. galloprovincialis & LOEC (7 days) & Membrane stability & $0.1[15]$ \\
\hline \multirow[t]{3}{*}{ Fish (adult) } & D. rerio & LOEC (6 weeks) & Egg production, oocytes, and kidney & $0.5[16]$ \\
\hline & D. rerio & $\operatorname{LOEC}(3,7$, and 15 days $)$ & DNA integrity & $0.31[17]$ \\
\hline & C. carpio & LOEC (28 days) & Cytopathology of the kidney & $1[11]$ \\
\hline
\end{tabular}

LOEC lowest observed effect concentration, ns not significant.

influence of other pharmaceuticals on this waste water and its dilution should be as low as possible.

For an effective ozonation, a low concentration of dissolved organic carbon (DOC) is important [29], and this is most likely true for other oxidative treatment processes. Therefore, the waste water loaded with antiepileptic drugs should be treated biologically prior to advanced treatment steps. A membrane bioreactor (MBR) is appropriate to eliminate DOC and additionally, due to filtration, emits only a small amount of suspended particles (which interfere with irradiation and oxidative processes).

In the study presented here, a hospital ward, specialized on epilepsy treatment, was chosen as source for waste water highly loaded with antiepileptic drugs. The waste water was treated biologically, analyzed for antiepileptic drugs, and tested for ecotoxicological effects. A standard test system for the assessment of ecotoxicity of treated waste water is the zebrafish (Danio rerio) embryo test [30,31]; additional endpoints are given in [32] and other publications. The central nervous system (CNS) of zebrafish has similarities with the human CNS, and some mammalian neurotransmitter systems are present [33]; the site of action of antiepileptic drugs is the human CNS.

Although the concentrations of antiepileptic drugs to be expected in the hospital waste water would not reach the effect concentrations for antiepileptic drugs on $D$. rerio (Table 3 ), possible effects of this complex mixture should be investigated. On the one hand, ecotoxicological data exist only for carbamazepine and phenytoin; on the other hand, according to [34], substances with similar targets can add their effects to each other and cause effects below the single substance effect concentrations. Due to the expected low dilution, possible additive effects, the incomplete data in the existing literature, and the similarity of CNS, toxic effects on $D$. rerio embryos seemed possible and worth investigating.

Because antiepileptic drugs take effect on the neuronal system and show some neurotoxicological effects (e.g., [37]), the biologically treated waste water was also tested with a newly introduced test for developmental neurotoxicity with $D$. rerio according to [38], where the motor neurons are stained.

To validate, if the chosen waste water is appropriate for further investigation of advanced treatment processes, the following steps were performed:

- Waste water loaded with antiepileptic drugs was treated with a MBR.

- Concentrations of antiepileptic drugs were determined in order to assess potential variations due to MBR treatment.

- Ecotoxicological tests with D. rerio were applied to MBR-treated waste water.

- In order to assess the developmental neurotoxicological effects in $D$. rerio, motor neurons were stained.

To our knowledge, this is the first work regarding biologically treated waste water of a ward in a neurological hospital specialized on epilepsy treatment which is screened for antiepileptic drugs and tested with $D$. rerio embryos. 
Table 3 Toxicological data for antiepileptic drugs, investigated in this study, regarding $D$. rerio embryo test

\begin{tabular}{|c|c|c|c|c|}
\hline Test & Species & Endpoint (time) & Endpoint & Effect concentration $\left(\mu \mathrm{g} \mathrm{L}^{-1}\right)$ \\
\hline \multicolumn{5}{|l|}{ Carbamazepine } \\
\hline \multirow[t]{4}{*}{ Fish (early life stage) } & D. rerio & LOEC (10 days) & Embryos and larvae mortality & $50,000[12]$ \\
\hline & & $\mathrm{EC}_{50}(72 \mathrm{~h})$ & Growth retardation & $86,500[35]$ \\
\hline & & $\mathrm{EC}_{20}(72 \mathrm{~h})$ & Tail malformation & $17,500[36]$ \\
\hline & & $\mathrm{EC}_{50}(72 \mathrm{~h})$ & Tail malformation & $52,500[36]$ \\
\hline \multicolumn{5}{|l|}{ Phenytoin } \\
\hline \multirow[t]{2}{*}{ Fish (early life stage) } & D. rerio & $\mathrm{EC}_{20}(72 \mathrm{~h})$ & Tail malformation & $10,000[36]$ \\
\hline & & $\mathrm{EC}_{50}(72 \mathrm{~h})$ & Tail malformation & $97,400[36]$ \\
\hline
\end{tabular}

\section{Results and discussion}

\section{Characterization of the raw waste water}

The results for the chemical oxygen demand (COD), given in Additional file 1: Table af1, show a high heterogeneity of the sampled raw waste water. This may be explained by the frequency of toilet flushes and occurrence of feces.

\section{Biological treatment}

Since the purpose of the biological treatment is the reduction of readily biodegradable substances and DOC concentration, no process monitoring was performed. The weighted mean of the COD was $222 \mathrm{mg} \mathrm{L}^{-1}$. The mean dried matter content of $2.1 \mathrm{~g} \mathrm{~L}^{-1}$, the reactor volume of $107 \mathrm{~L}$, and a load of $315 \mathrm{~L}$ raw waste water in 10 days resulted in a biochemical oxygen demand $\left(\mathrm{BOD}_{5}\right)$ load of $16 \mathrm{mg} \mathrm{BOD}_{5}(\mathrm{~g} \mathrm{TS})^{-1}$ day $^{-1}$ (assuming a COD/ $\mathrm{BOD}_{5}$ ratio of 2:1). The membrane flux was approximately $21 \mathrm{~L}\left(\mathrm{~h} \text { bar } \mathrm{m}^{2}\right)^{-1}$. The detention period of theoretically $80 \mathrm{~h}$ was much higher than the typical $8 \mathrm{~h}$ of a municipal waste water treatment plant.

\section{Characterization of the biologically treated waste water}

The total amount of biologically treated waste water was approximately $320 \mathrm{~L}$. The modeled fractions originating from raw waste water of the hospital was $59 \%$. The biologically treated waste water, stored at $4^{\circ} \mathrm{C}$, showed a concentration of dissolved organic carbon of 5 to $6 \mathrm{mg} \mathrm{L}^{-1}$ (quadruple determination), a $\mathrm{pH}$ of 7.3, and an electrical conductivity of $0.71 \mathrm{~ms} \mathrm{~cm}^{-1}$ (single determinations). The results of the multi-elemental analysis (single determination), given in Additional file 1: Table af2, show a low $\mathrm{Cu}$ load, which is important for ecotoxicological test systems.

\section{Estimation of the behavior of antiepileptic drugs during MBR treatment}

Based on the measured concentrations of antiepileptic drugs in the raw waste water samples and their modeled fractions of the biologically treated waste water, the concentrations to be expected in the mixed sample after MBR passage without transformation were calculated.
These modeled concentrations were compared to the concentrations measured in the biologically treated waste water in Figure 1. The underlying results of raw waste water samples, given in Additional file 1: Figure af1, show high variations of antiepileptic drug concentrations over time.

For interpretation of Figure 1, it has to be taken into account that the measured concentrations are based on single determinations. Additionally, raw waste water contains much higher concentrations of organic compounds, which could overload the solid phase extraction (SPE) cartridges and cause matrix effects in the mass spectrometer. The internal standard 10,11-dihydrocarbamazepine was used to account for cartridge capacity. Because the aim of the analysis was to perform an estimation on the behavior and the expected analyte concentrations were high, the use of surrogate standards for elimination of possible matrix effects was omitted.

According to the estimation, partial elimination of 10hydroxy-10,11-dihydrocarbamazepine (10-OH carbamazepine) and rufinamide and some release of lamotrigine, oxcarbazepine and, possibly, primidone occurred. The other investigated substances did not distinctly change concentrations due to this biological treatment in the MBR.

The elimination of 10-OH carbamazepine is contrary to the findings in [39], wherein the authors found a release of 10-OH carbamazepine in a WWTP. For lamotrigine, no data about its behavior in WWTP were found in the literature, but the authors in [40] found a large portion of lamotrigine in WWTP effluent in the 2-N-glucuronidated form (see Table 4). Deglucuronidation, which occurs in WWTPs (e.g., [41]), presumably led to the release of lamotrigine. The release of oxcarbazepine is also contrary to the literature; in [39], the authors found an elimination rate of $25 \%$ to $73 \%$ in WWTPs. In [42], the authors found no elimination of primidone and a release of phenylethylmalonamide and phenobarbital in a WWTP, which is in general accordance with the presented data. For rufinamide, lamotrigine, lacosamide, and zonisamide, no data were found in the literature. 


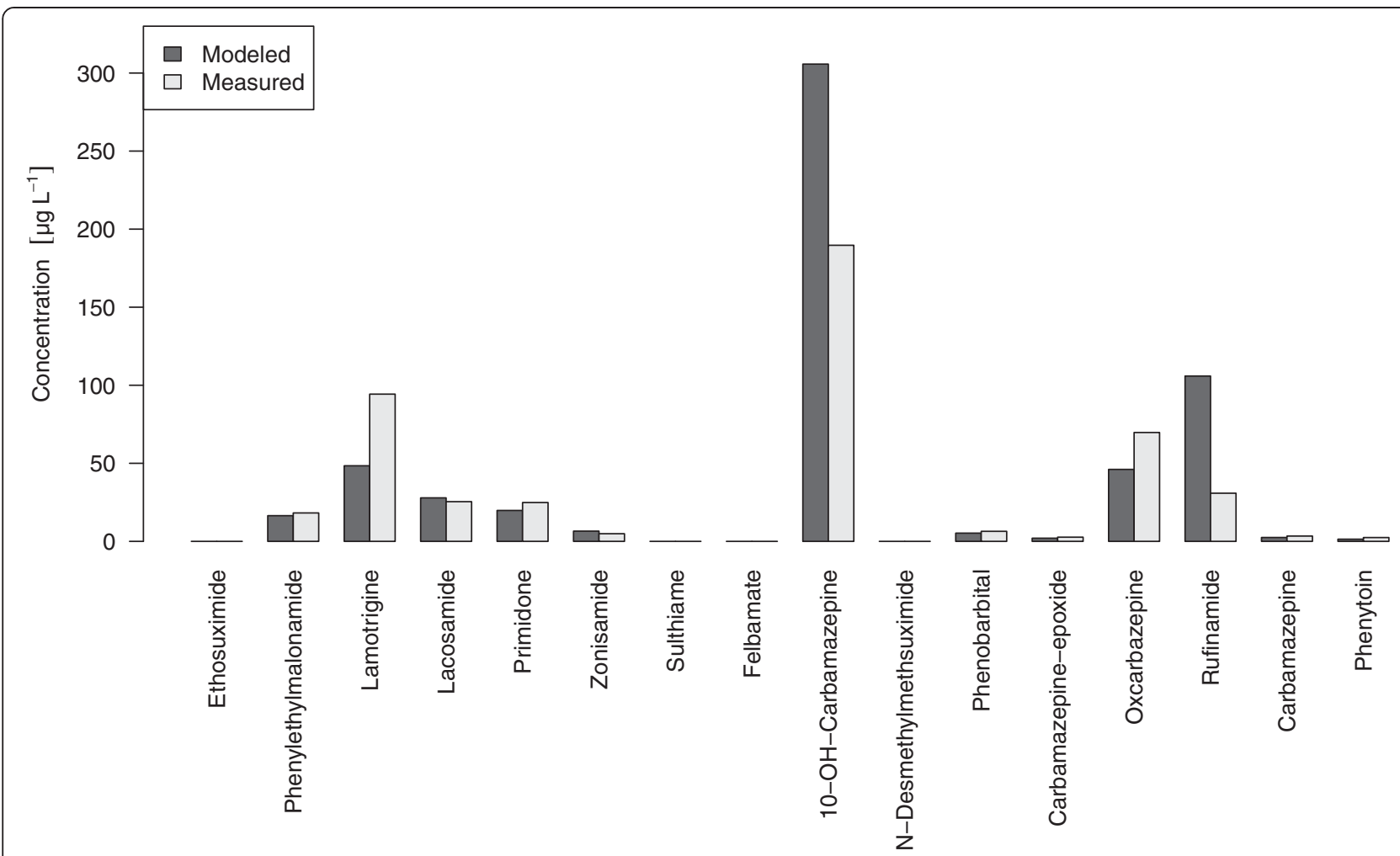

Figure 1 Comparison of modeled and measured concentrations for biologically treated waste water. Modeled concentrations consist of results from raw waste water samples and their fractions on the biologically treated waste water.

The missing elimination of oxcarbazepine possibly resulted from missing sunlight under pilot scale conditions, since UV leads to degradation of oxcarbazepine according to [26]. Additionally to missing sunlight, the low $\mathrm{BOD}_{5}$ load may have resulted in lower co-metabolization rates (e.g., [47]). However, results of oxcarbazepine showed a high variation (see Figure 2) and should be considered carefully.

The results suggest that biological treatment with the membrane bioreactor was not sufficient to considerably eliminate the antiepileptic drugs investigated, which is (fate of oxcarbazepine excepted) in good agreement with the data found in the literature.

In prospective biological treatments of loaded raw waste water, the dilution, caused by starting conditions of the MBR and sludge exchange, should be minimized by the use of a smaller reactor volume, bigger membrane area, and higher $\mathrm{BOD}_{5}$ load. Sludge exchange should be avoided, if possible.

\section{Antiepileptic drugs in the biologically treated waste water}

Due to single determinations, the results of the previous analysis of biologically treated waste water are of limited significance. Therefore, the analysis of the stored $\left(4^{\circ} \mathrm{C}\right)$, biologically treated waste water was repeated with four different SPE procedures.

The calibration points using hydrophilic-lipophilic balance (HLB) and polar enhanced polymer (PEP) SPE cartridges were generally in good accordance so that they were used together in the calibration curve. The only exception was ethosuximide, whose mean recovery rate in SPE extraction was $38 \%$ with a high variation. Nevertheless, both SPE calibration points were used, to include the recovery rate, and the directly injected standards were discarded from the calibration curve of ethosuximide.

The results of the analysis are shown in Figure 2. The highest concentrated substances were $10-\mathrm{OH}$ carbamazepine (which is a metabolite of carbamazepine and oxcarbazepine), lamotrigine, and oxcarbazepine.

Contrary to the previous analysis, now ethosuximide could be detected in the biologically treated waste water. The reason lies presumably in the low recovery rate, which may have led to a cartridge breakthrough due to the higher preconcentration factor in the previous analysis. Apart from that, the results for the biologically treated waste water obtained under the use of the two different SPE cartridges are in good agreement with the previous results (oxcarbazepine excepted). 
Table 4 Maximum concentrations of antiepileptic drugs used in this study in municipal WWTP effluents and rivers

\begin{tabular}{|c|c|c|}
\hline Analyte & $\begin{array}{l}\text { Concentration at } \\
\text { WWTP effluents } \\
\left(\mu \mathrm{g} \mathrm{L}^{-1}\right)\end{array}$ & $\begin{array}{l}\text { Concentration in } \\
\text { rivers and streams } \\
\left(\mu \mathrm{g} \mathrm{L}^{-1}\right)\end{array}$ \\
\hline \multirow[t]{3}{*}{ Carbamazepine } & $6.3(\mathrm{DE})[3]$ & $1.1(\mathrm{DE})[3]$ \\
\hline & $21.6(\mathrm{KR})[4]$ & $0.3(\mathrm{UK})[5]$ \\
\hline & $4.6(\mathrm{UK})[5]$ & \\
\hline Ethosuximide & No data & No data \\
\hline Phenylethylmalonamide & 0.37 (DE) [43] & 0.11 (DE) [43] \\
\hline \multirow[t]{2}{*}{ Lamotrigine } & 0.488 (USA) [40] & 0.108 (USA) [40] \\
\hline & $1.2($ USA) [6] & \\
\hline Lamotrigine 2-N-glucuronide & 0.209 (USA) [40] & 0.195 (USA) [40] \\
\hline Lacosamide & No data & No data \\
\hline Primidone & 0.71 (DE) [43] & 0.18 (DE) [43] \\
\hline Zonisamide & No data & No data \\
\hline Sulthiame & No data & No data \\
\hline Felbamate & No data & No data \\
\hline \multirow[t]{2}{*}{ 10-OH-Carbamazepine } & 1.17 (FR) [39] & No data \\
\hline & 1.9 (USA) [6] & \\
\hline N-Desmethylmethsuximide & No data & No data \\
\hline \multirow[t]{2}{*}{ Oxcarbazepine } & $0.129(\mathrm{FR})[39]$ & No data \\
\hline & 0.48 (USA) [6] & \\
\hline Rufinamide & No data & No data \\
\hline Phenytoin & 0.25 (USA) [44] & 0.004 (USA) [45] \\
\hline \multicolumn{3}{|c|}{ Metabolites of antiepileptic drugs } \\
\hline Phenobarbital & 0.21 (DE) [43] & 0.05 (DE) [43] \\
\hline Carbamazepine epoxide & $0.029(F R)[39]$ & $0.077(\mathrm{NO})[46]$ \\
\hline
\end{tabular}

Exemplary data, not exhaustive. FR France, DE Germany, KR Republic of Korea, NO Norway, USA United States of America.

The total load of the analyzed pharmaceutically active substances was approximately $400 \mu \mathrm{g} \mathrm{L}^{-1}$, which is more than 15-fold higher than to be expected at WWTP effluents in Europe or the USA according to concentrations given in Table 3 (the mean concentration of $1 \mu \mathrm{g} \mathrm{L} \mathrm{L}^{-1}$ was assumed for substances without existing data). Considering the modeled portion of $59 \%$ hospital raw waste water in the biologically treated waste water, this rough estimation would result in a 25 -fold higher load.

This confirms the low dilution due to missing rain water and due to the homogeneity of the group of patients. However, the contribution of the ward to the mass flow of the corresponding waste water treatment plant will be low due to the widespread use of antiepileptic drugs.

Due to the low concentration of dissolved organic carbon and the relatively high load of antiepileptic drugs, this biologically treated waste water, originating from an epilepsy ward, is appropriate for the investigation of the behavior of antiepileptic drugs in advanced waste water treatment processes.

\section{Embryo tests on biologically treated waste water}

No morphological differences between the embryos exposed to biologically treated waste water and the controls in tests with durations of 48, 72, and $96 \mathrm{~h}$ could be detected. The overall mortality in valid tests was less than $7 \%$. The results of heartbeat frequency after $96 \mathrm{~h}$ are shown in Figure 3.

Oxcarbazepine solution was used for comparison with a highly concentrated antiepileptic drug. The tested oxcarbazepine solution was saturated at $26^{\circ} \mathrm{C}$; a solubility test showed a concentration of $8.7 \pm 0.3 \mathrm{mg} \mathrm{L}^{-1}$. Toxicity tests of $10-\mathrm{OH}$ carbamazepine and lamotrigine, which were also present at high concentrations in the biologically treated waste water, should be performed with $D$. rerio. There were no significant differences regarding the primary and secondary motor neurons between embryos treated with biologically treated waste water and the control.

Weigt et al. [36] have shown that D. rerio embryos are able to metabolize (and therefore activate) proteratogens and conclude from their results that $D$. rerio embryos show phase I enzymatic activity at very early developmental stages. Therefore, a metabolization of test compounds during the test can be assumed. It should be tested if there is a significant change of antiepileptic drug concentrations due to metabolization.

Until now, only a small amount of ecotoxicological data exist for antiepileptic drugs in the literature (exception: carbamazepine). Therefore, additional ecotoxicological tests should be conducted on this biologically treated waste water. A test system probably sensitive enough to show effects (derived from its sensitivity to carbamazepine) is Mytilus galloprovincialis [15], although this is a salt water organism.

For the investigation of advanced waste water treatment processes, the micro-algae Nitzschia sigma should additionally be tested because of its sensitivity to acridine (EC 50 growth inhibition $80 \mu \mathrm{g} \mathrm{L}^{-1}$ [48]).

\section{Conclusion}

Biological treatment of the raw hospital waste water by a pilot scale membrane bioreactor was successful regarding the low dissolved organic carbon concentration and low oxygen consumption in the treated water. This allowed ecotoxicological testing of this highly contaminated water with embryos of $D$. rerio.

Biological treatment caused some elimination of $10-\mathrm{OH}$ carbamazepine and rufinamide but was not sufficient for significant elimination of the load of antiepileptic drugs investigated, which is in general accordance with the 

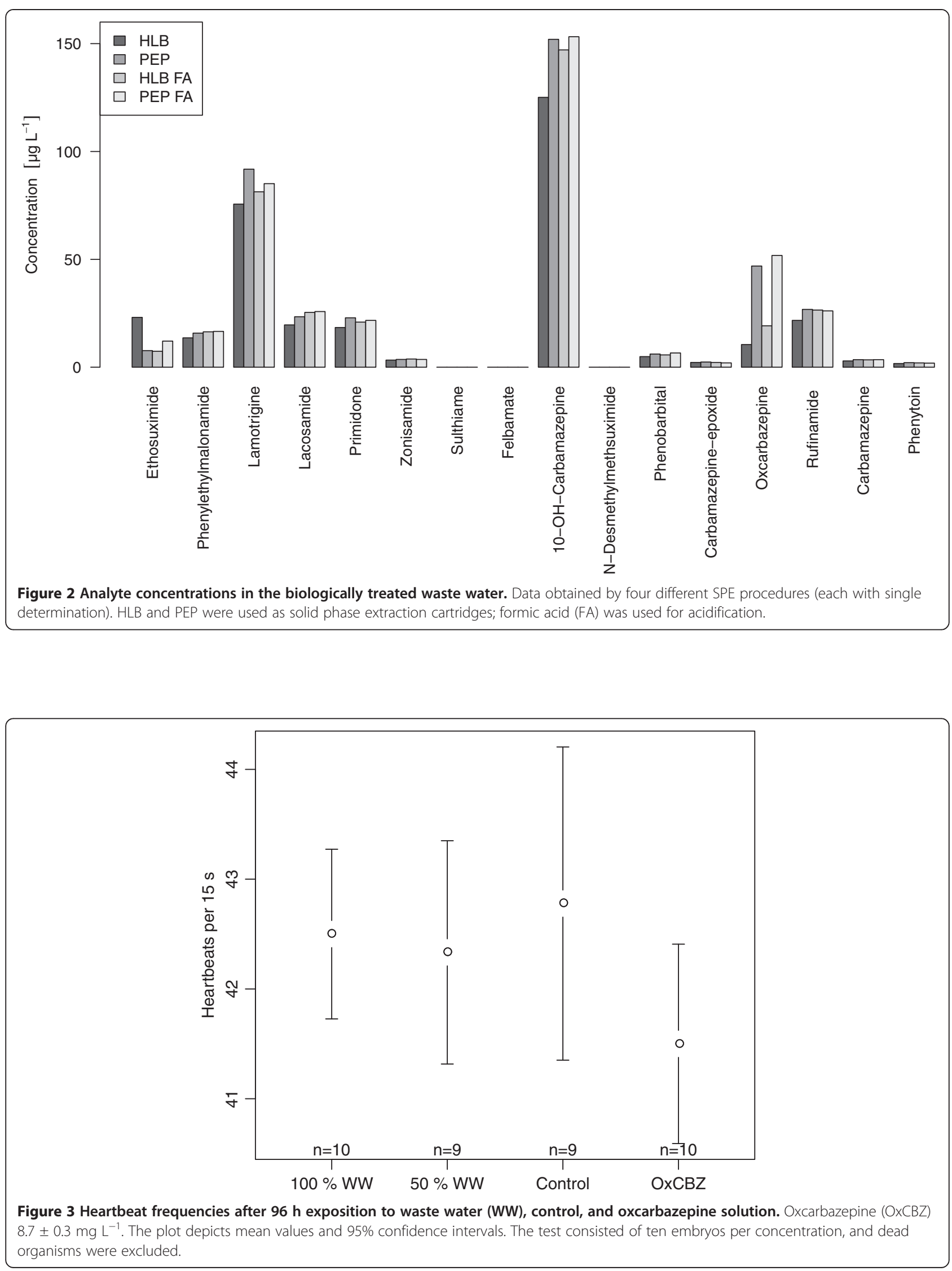
literature. The highest concentrated substances found were 10-OH carbamazepine, lamotrigine, and oxcarbazepine.

The complex substance mixture of the treated waste water from a ward located in a neurological hospital, which is specialized on epilepsy treatment, had neither toxic effects on $D$. rerio morphology nor on the development of the primary and secondary motor neurons (indicator for developmental neurotoxicity). An oxcarbazepine solution of $8.7 \pm 0.3 \mathrm{mg} \mathrm{L}^{-1}$ had no morphological effects on $D$. rerio embryos. Biologically treated waste water originating from an epilepsy ward is appropriate for investigation of the fate of antiepileptic drugs in advanced treatment processes.

\section{Methods}

\section{Waste water sampling}

Sampling took place on Thursday, 28 June 2012, a hot dry summer day, from 12:05 p.m. until 16:30 p.m. at the waste water collector from an epilepsy ward and an epilepsy ambulance of an anonymous neurological hospital in Germany. The water was pumped out of the sewer with two 10-mm polytetrafluoroethylene (PTFE) tubes aligned parallel to the flow direction. A small barrier, located approximately $5 \mathrm{~cm}$ behind the openings of the tubes, was used to slightly raise the water level. With this strategy the more or less constantly flowing dilution water (e.g., from basins) was mainly discarded, and only the water of the toilet flushes was collected.

Because the concentrations of antiepileptic drugs to be expected depend on the patients present during sampling time, a generally high variability will occur. As a result of regular plugging of the tubes due to toilet paper and feces, continuous control of the pump was necessary. The aim of this sampling was to get waste water highly loaded with antiepileptic drugs and not the description of representative mass flows of antiepileptic drugs from this hospital ward. Therefore, the sampling was done in 1 day. A total volume of $c a$. 320-L raw waste water was collected in new, RO water cleaned low-density polyethylene $(\mathrm{LD}-\mathrm{PE})$ canisters $(9 \times 25 \mathrm{~L}, 3 \times 30 \mathrm{~L}$, filled above the nominal mark) and stored until treatment at $4^{\circ} \mathrm{C}$.

\section{Waste water treatment}

The raw waste water was treated in a MBR with a ceramic membrane (200-nm pore size, Type G 200, kindly provided by ITN Nanovation AG, Saarbrücken, Germany). The flow chart of the MBR is shown in Figure 4. All materials with direct water contact after membrane passage were of PTFE, stainless steel, high-density polyethylene (HD-PE), or (in case of the membrane housing) polyethersulfone (PES) and polyurethane (PU). The treatment cycle was as follows: After starting the re-filling process of the MBR with raw waste water, the aeration stopped for $30 \mathrm{~min}$ to reach anoxic conditions. Then, 2:30-min filtration with 0:10-min pause continued cyclic under constant aeration until the filtrate box was filled $(5 \mathrm{~L}$, duration ca. $3 \mathrm{~h}$ ), which triggered the re-filling of the MBR. Re-filling was performed with a peristaltic pump from the clear supernatant of the raw waste water; the particle loaded bottom was discarded. The MBR had a volume of $107 \mathrm{~L}$ and was constantly stirred. It was initially filled with activated sludge from the last aeration tank before the clarifier of the waste water treatment plant in Giessen, Germany. Prior to use, it was washed twice with tap water via sedimentation to reduce the impact of the municipal waste water. The treatment was conducted in three separate batches $(2.5,4$, and 3 days,

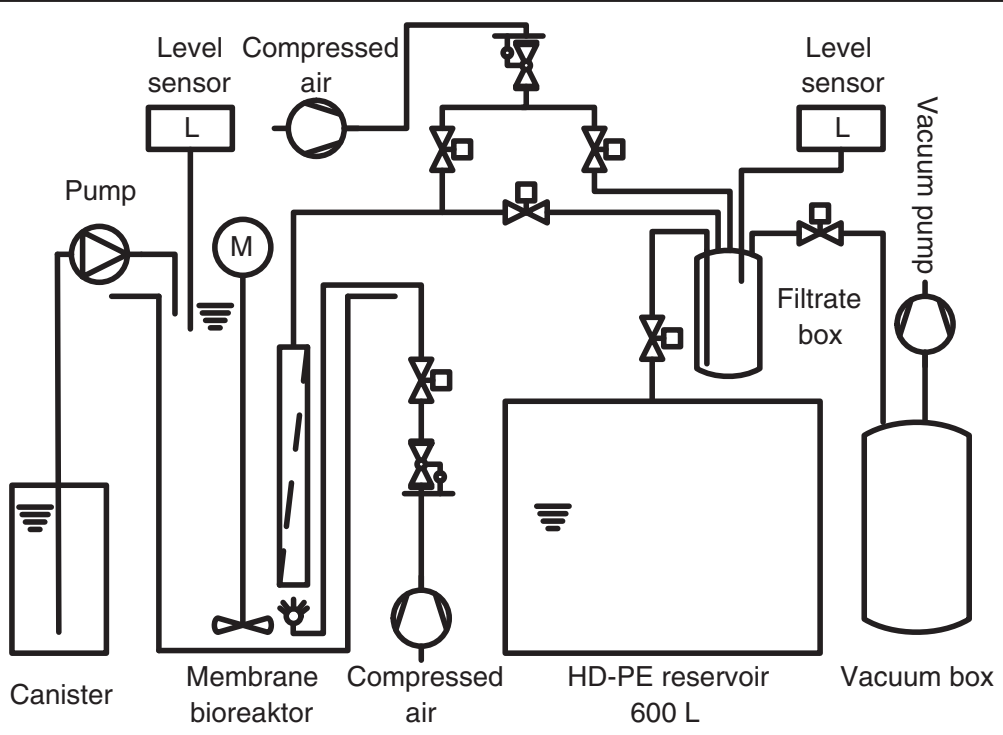

Figure 4 Flow chart of the membrane bioreactor. 
respectively), for which fresh sludge was used; the decanted water of the prior batch was reused to reduce dilution of the waste water. The biologically treated waste water was collected in a 600-L HD-PE reservoir, which was aerated during treatment, and then stored at $4^{\circ} \mathrm{C}$ until further use. The term biologically treated waste water used in this publication refers to this mixed sample.

\section{Water analysis}

The COD of filtrated $(0.45-\mu \mathrm{m}$ polyethylene terephthalate $(\mathrm{PET})$ ) raw waste water samples, which were stored frozen before analysis, was quantified with cuvette tests (Hach-Lange, Düsseldorf, Germany). The DOC of the biologically treated waste water, which was stored at $4^{\circ} \mathrm{C}$ until analysis, was tested with cuvette tests (Hach-Lange). The cations of the biologically treated waste water were analyzed with an ICP-OES (720-ES, Varian, Darmstadt, Germany).

\section{Estimation of antiepileptic drug degradation due to biological treatment}

To allow the assessment of a possible biological degradation of antiepileptic drugs during MBR treatment, raw waste water and biologically treated waste water were analyzed for these substances. For preconcentration and cleanup, Oasis HLB (60 mg, $3 \mathrm{~mL}$ ) SPE cartridges conditioned with $5 \mathrm{~mL}$ methanol and equilibrated with $5 \mathrm{~mL}$ Milli-Q (Merck Millipore, Darmstadt, Germany) water were used. The samples of raw waste water (stored at $-32^{\circ} \mathrm{C}$ ) were thawed; the treated waste water (stored at $4^{\circ} \mathrm{C}$ ) was brought to room temperature. Twenty-five milliliters of decanted, unfiltrated samples were spiked with $50-\mu \mathrm{L}$ solution of 10,11-dihydrocarbamazepine $\left(12.5 \mathrm{mg} \mathrm{L}^{-1}\right)$ for internal standardization and forced, via peristaltic pump, through the cartridges with $1 \mathrm{ml} \mathrm{min}{ }^{-1}$. For identification and calibration of the analytes, $\mathrm{ClinCal}^{\oplus}$ serum calibrators 15013 and 15213 (Recipe, Germany) were diluted, mixed together, spiked with internal standard, and prepared as waste water samples to get a 2-point calibration with preconcentration factors of 0.6 and 0.3 for 15013 and 0.4 and 0.2 for 15213 .

After extraction, the cartridges were dried for $30 \mathrm{~min}$ under vacuum and then eluted with $5 \mathrm{~mL}$ acetonitrile. The extract was evaporated to dryness under a gentle stream of nitrogen at room temperature. The analytes were then resolved in $200 \mu \mathrm{L}$ acetonitrile. After thorough rinsing of all surfaces, $300 \mu \mathrm{L}$ Milli-Q water was added; the sample was mixed and then filtrated with $0.45-\mu \mathrm{m}$ PTFE syringe filters. Calibration points were prepared twice and samples once.

For each raw waste water sample, the fraction on the biologically treated waste water was modeled, based on the canister volume, time of introduction in the MBR, the sludge exchanges (after 2.5 and further 4 days, in which $47 \mathrm{~L}$ of water and sludge were exchanged due to treatment break), and removal from the system due to filtration. The fraction of each raw waste water sample on the biologically treated waste water was calculated with the sum of filtrated volumes. A water loss (without analyte loss) of $20 \mathrm{~L}$ due to evaporation was assumed. These modeled fractions were used to calculate the concentrations of antiepileptic drugs to be expected in the mixed sample after MBR passage considering the abovementioned factors without any transformation process.

\section{Antiepileptic drugs in biologically treated waste water}

To confirm the concentrations of antiepileptic drugs in the biologically treated waste water, an additional screening with two different SPE cartridges and a lower preconcentration factor was applied. Additionally to the uncontrolled conditions, the same conditions as in highperformance liquid chromatography (HPLC) gradient ( $0.1 \%$ formic acid) were used, resulting in a $\mathrm{pH}$ below 2.8 .

For preconcentration and cleanup, Oasis HLB (60 mg, $3 \mathrm{~mL}$ ) and Thermo HyperSep Retain PEP (60 mg, $3 \mathrm{~mL}$ ) SPE cartridges, each conditioned with $5 \mathrm{~mL}$ methanol and equilibrated with $5 \mathrm{~mL}$ Milli-Q water, were used. For sample extraction, $10 \mathrm{~mL}$ of treated waste water were mixed with $15 \mathrm{~mL}$ Milli-Q water and forced via peristaltic pump through the cartridges with $1 \mathrm{ml} \mathrm{min}^{-1}$. Drying, elution, evaporation, resolving, and filtration were performed as described above.

For identification and calibration of the analytes, Clintest ${ }^{\oplus}$ standards 15011, 14011, and 14111 (Recipe, Germany) were used. While 15011 was diluted and then preconcentrated like waste water samples (preconcentration factor 1, $1 \times$ HLB, 1× PEP), 14011 and 14111 were measured without further preparation.

\section{Mass spectrometric analysis of antiepileptic drugs}

Antiepileptic drugs and pharmacologically active metabolites were measured with liquid chromatography/timeof-flight mass spectrometry (LC-TOF-MS) consisting of a Dionex Ultimate 3000 HPLC (Thermo Fisher Scientific, Idstein, Germany) equipped with a Dionex Polar Advantage II column $(2.1 \times 150 \mathrm{~mm}, 3 \mu \mathrm{m})$. The detection was performed with a Bruker micrOTOF-QII (Bremen, Germany) in positive electrospray ionization (ESI) mode with a mass range of 50 to $500 \mathrm{~m} \mathrm{z}^{-1}$; for mass calibration, Li formate was used.

The mobile phase consisted of $0.1 \%$ formic acid (FA) in Milli-Q water (A) and $90 \%$ acetonitrile with $10 \%$ of $0.1 \%$ FA in Milli-Q water (B); the gradient of A was 0 $\min 91 \%, 5 \min 83 \%, 15 \min 75 \%, 25 \operatorname{min~55\% ,~} 30 \mathrm{~min}$ $55 \%$, $35 \mathrm{~min} 20 \%$, $45 \mathrm{~min} 20 \%$, $47 \mathrm{~min} 91 \%$, and $60 \mathrm{~min}$ $91 \%$. Identification of the analytes was performed with 
the standards according to the mass signatures from literature given in Table 5 and (in case of equal masses) the elution order. To eliminate noise and artifacts as good as possible, the exact masses given in Table 5 were determined with the standards, and the mass window for quantification was set to $\pm 0.01 \mathrm{mz}^{-1}$.

\section{Solubility of oxcarbazepine}

One of the toxicological tests was performed with a saturated oxcarbazepine solution. To reconstruct this concentration, a solubility test was conducted. An excess amount of oxcarbazepine ( $>98 \%$, Sigma-Aldrich, St. Louis, MO, USA) was mixed in moderately hard synthetic freshwater [57] (target concentration $10 \mathrm{mg} \mathrm{L}^{-1}$ ) in a light-protected flask. After agitation for 3 days at room temperature, the solution was tempered 3 days at $26^{\circ} \mathrm{C} \pm$ $1^{\circ} \mathrm{C}$ in a water bath without agitation. The solution was filtrated with tempered syringe filters $(0.45-\mu \mathrm{m}$ PET) in tempered vials four times, and each was diluted 1:1 with methanol immediately to prevent precipitation. A 3-point calibration $\left(1,5\right.$, and $\left.10 \mathrm{mg} \mathrm{L}^{-1}\right)$ was used. Concentrations of oxcarbazepine were measured with an Agilent 1200 HPLC (Waldbronn, Germany); detection was performed with a diode array detector (G1315B, Agilent) at $254.8 \mathrm{~nm}$. Column and gradient were the same as in LC-TOF-MS analysis.

Table 5 Mass windows used for the measured analytes and concentrations found in the literature

\begin{tabular}{|c|c|c|c|}
\hline Analyte & $\begin{array}{l}\text { Retention } \\
\text { time (min) }\end{array}$ & $\begin{array}{c}\text { Used mass } \\
\text { window } \\
\left( \pm 0.01 \mathrm{mz}^{-1}\right)\end{array}$ & $\begin{array}{l}\text { Mass given in } \\
\text { the literature }\end{array}$ \\
\hline Ethosuximide & 6.6 & 142.085 & $142.0[49]$ \\
\hline Phenylethylmalonamide & 6.7 & 207.112 & $207.0[42]$ \\
\hline Lamotrigine & 9.1 & 256.013 & $256.1[49]$ \\
\hline Lacosamide & 9.9 & 251.137 & $251.2[50]$ \\
\hline Primidone & 10.1 & 219.111 & $219.1[51]$ \\
\hline Zonisamide & 11.2 & 213.031 & $213.1[49]$ \\
\hline Sulthiame & 11.5 & 291.044 & $291.0[52]$ \\
\hline Felbamate & 12.9 & 178.085 & $178.2[49,53]$ \\
\hline 10-OH-Carbamazepine & 16.3 & 255.111 & $255[54]$ \\
\hline $\begin{array}{l}N \text { - } \\
\text { Desmethylmethsuximide }\end{array}$ & 17.2 & 190.086 & $190.1[49]$ \\
\hline Phenobarbital & 17.8 & 233.090 & 231.2 [49], neg \\
\hline Carbamazepine epoxide & 19.2 & 253.095 & $253.2[49]$ \\
\hline Oxcarbazepine & 21.4 & 253.095 & $253.1[55]$ \\
\hline Rufinamide & 13.2 & 239.072 & $239.1[56]$ \\
\hline Carbamazepine & 25.0 & 237.101 & $237.1[49]$ \\
\hline $\begin{array}{l}\text { 10,11- } \\
\text { Dihydrocarbamazepine }\end{array}$ & 25.1 & 239.116 & \\
\hline Phenytoin & 27.2 & 253.095 & 253.2 [49] \\
\hline
\end{tabular}

neg negative polarity was used.

\section{Toxicological tests}

\section{Fish maintenance}

Approximately one hundred $D$. rerio were maintained in a 120 - $\mathrm{L}$ tank at $26^{\circ} \mathrm{C}$ with $10: 14$-h light/dark cycle and fed two times daily with Tetramin ${ }^{\oplus}$ (Tetra, Melle, Germany) and once per workday with artemia. For egg production, a spawning dish, covered with a stainless steel mesh and artificial plants, was introduced in the tank before lights out and removed 30 to $45 \mathrm{~min}$ after lights on at the day of the test. The eggs were washed with control and then randomly put in a beaker filled with 20 -mL test solution at the latest $2 \mathrm{~h}$ after lights on; from there, they were sorted to the test vessels (4-mL glass vessels with $3-\mathrm{mL}$ test solution).

\section{Tests with $D$. rerio}

After controlling the vitality and morphology of the embryos, the vessels were put into the incubator at $26^{\circ} \mathrm{C}$ with 12:12-h light/dark cycle for the duration of the test. The control was prepared as moderately hard synthetic freshwater according to [57]. The test solutions were brought to test temperature and vented for a minimum of 15 min prior to exposition of the embryos. According to [31], the $\mathrm{pH}$ of the sample and control was not adjusted, given that it was within the limits of 6.5 to 8.5. For counting of the heartbeat, one vessel was removed from the incubator, put without delay on the inverse microscope (Olympus IM, Hamburg, Germany) for counting and, after examination of the morphology, put back into the incubator, so that the temperature of the vessel while counting was the same for each embryo. All examinations were done blinded.

Lethal endpoints, sublethal endpoints, and endpoints of teratogenicity in the fish embryo test (FET) were selected for 48 and $96 \mathrm{~h}$ according to [32] with emphasis on the heartbeat frequency. Tests were treated as valid when the mortality of the control was $10 \%$ or smaller.

Valid tests were conducted at $48 \mathrm{~h}$ (three samples + control with 20 embryos; two samples + control with 15 embryos $^{\mathrm{a}}$ ), $72 \mathrm{~h}$ (three samples + control with 15 embryos $^{\mathrm{a}}$ ), and $96 \mathrm{~h}$ (two samples + control with 10 embryos). No repetitions were done.

For assessment of developmental neurotoxicity, also the primary and secondary motor neurons of 48-h-old embryos were stained and rated according to the method previously published by Muth-Köhne et al. [38] which was adapted as follows: The fixed embryos were permeabilized and directly blocked in blocking solution (phosphate-buffered saline (PBS)/4\% ( $v / v)$ Triton X-100/ $10 \%(v / v)$ normal goat serum) for $30 \mathrm{~min}$ at room temperature and constant agitation and then incubated with the primary antibody $(5 \mu \mathrm{g} / \mathrm{mL}$ in blocking solution) overnight at $4^{\circ} \mathrm{C}$. The used chemicals and tools 
were identical to the published method. The examination of the stained motor neurons and the rating of defects were done blinded. The test was conducted at $48 \mathrm{~h}$ (two samples + control with 15 embryos of which 13 to 14 were used).

\section{Endnote}

${ }^{a}$ Embryos were controlled for vitality and then fixed; morphology was assessed on fixed embryos.

\section{Additional file}

Additional file 1: Chemical oxygen demand, multi-elemental analytics, and antiepileptic drug concentrations. Table af1. Chemical oxygen demand (COD) of raw waste water samples. Table af2. Results of multi-elemental analytics for biologically treated waste water with ICP-OES $\left(\mathrm{mg} \mathrm{L}^{-1}\right)$. Figure af1. Antiepileptic drug concentrations for raw waste water samples.

\section{Abbreviations}

$\mathrm{BOD}_{5}$ : Biochemical oxygen demand in 5 days; CNS: Central nervous system; COD: Chemical oxygen demand; DOC: Dissolved organic carbon; EC 20 : Effect concentration at which $20 \%$ of the organisms show an effect; $E_{50}$ : Effect concentration at which $50 \%$ of the organisms show an effect; FA: Formic acid; HD-PE: High-density polyethylene; LC: Liquid chromatography; LD-PE: Low-density polyethylene; LOEC: Lowest observed effect concentration; MBR: Membrane bioreactor; OxCBZ: Oxcarbazepine; PBS: Phosphate-buffered saline; PES: Polyethersulfone; PET: Polyethylene terephthalate; PTFE: Polytetrafluoroethylene; PU: Polyurethane; SPE: Solid phase extraction; TOF-MS: Time-of-flight mass spectrometer; $10-\mathrm{OH}$ carbamazepine: 10-hydroxy-10,11-dihydrocarbamazepine.

\section{Competing interests}

The authors declare that they have no competing interests.

\section{Authors' contributions}

$\mathrm{CH}$ and R-AD planned the study. $\mathrm{CH}$ constructed the MBR, conducted the sampling and treatment of the waste water, performed the LC-TOF-MS analytics, conducted the embryo tests, and interpreted the results. EM-K conducted the staining of the motor neurons and interpreted and rated the defects. $\mathrm{CH}$ took part in the staining of the motor neurons. $\mathrm{CH}$ drafted the manuscript. $\mathrm{CH}$ and $\mathrm{R}-\mathrm{AD}$ reworked the manuscript critically. All authors read and approved the final manuscript.

\section{Acknowledgements}

We thank René Röhrich of the Fraunhofer Institute for Molecular Biology and Applied Ecology for his support at the HPLC with time of flight mass spectrometry. We also thank Christian Schinz from the Institute of Analytical Chemistry and Thomas Nimmerfroh of the I. Physical Institute, both in the University of Giessen, and their teams for providing the custom-made parts of the membrane bioreactor. We acknowledge BANSS Foundation for funding the construction material and consumables.

\section{Author details}

${ }^{1}$ Institute of Soil Science and Soil Conservation and Research Centre for BioSystems, Land Use and Nutrition (IFZ), Heinrich-Buff-Ring 26-32, Giessen 35392, Germany. ${ }^{2}$ Fraunhofer Institute for Molecular Biology and Applied Ecology IME, Forckenbeckstraße 6, Aachen 52074, Germany.

Received: 18 June 2013 Accepted: 25 September 2013 Published: 7 October 2013

\section{References}

1. Garrison AW, Pope JD, Allen FR: GC/MS analysis of organic compounds in domestic wastewaters. In Identification and Analysis of Organic Pollutants in Water. Edited by Keith $\mathrm{CH}$. Michigan: Ann Arbor Science Publishers; 1976:517-556.
2. Hignite C, Azarnoff DL: Drugs and drug metabolites as environmental contaminants: chlorophenoxyisobutyrate and salicylic acid in sewage water effluent. Life Sci 1977, 20:337-341.

3. Ternes TA: Occurrence of drugs in German sewage treatment plants and rivers. Water Res 1998, 32:3245-3260.

4. Sim W, Lee J, Lee E, Shin S, Hwang S, Oh J: Occurrence and distribution of pharmaceuticals in wastewater from households, livestock farms, hospitals and pharmaceutical manufactures. Chemosphere 2011, 82:179-186.

5. Kasprzyk-Hordern B, Dinsdale RM, Guwy AJ: The removal of pharmaceuticals, personal care products, endocrine disruptors and illicit drugs during wastewater treatment and its impact on the quality of receiving waters. Water Res 2009, 43:363-380.

6. Writer JH, Ferrer I, Barber LB, Thurman EM: Widespread occurrence of neuro-active pharmaceuticals and metabolites in 24 Minnesota rivers and wastewaters. Sci Total Environ 2013, 461-462:519-527.

7. Miège $C$, Choubert J, Ribeiro $L$, Eusèbe $M$, Coquery M: Fate of pharmaceuticals and personal care products in wastewater treatment plants - conception of a database and first results. Environ Pollut 2009, 157:1721-1726.

8. Ratola N, Cincinelli A, Alves A, Katsoyiannis A: Occurrence of organic microcontaminants in the wastewater treatment process. A mini review. J Hazard Mater 2012, 239-240:1-18.

9. Contardo-Jara V, Lorenz C, Pflugmacher S, Nützmann G, Kloas W, Wiegand C. Exposure to human pharmaceuticals Carbamazepine, Ibuprofen and Bezafibrate causes molecular effects in Dreissena polymorpha. Aquat Toxicol 2011, 105:428-437.

10. Triebskorn R, Casper H, Heyd A, Eikemper R, Köhler H, Schwaiger J: Toxic effects of the non-steroidal anti-inflammatory drug diclofenac. Aquat Toxicol 2004, 68:151-166.

11. Triebskorn R, Casper H, Scheil V, Schwaiger J: Ultrastructural effects of pharmaceuticals (carbamazepine, clofibric acid, metoprolol, diclofenac) in rainbow trout (Oncorhynchus mykiss) and common carp (Cyprinus carpio). Anal Bioanal Chem 2007, 387:1405-1416.

12. Ferrari B, Paxéus N, Lo Giudice R, Pollio A, Garric J: Ecotoxicological impact of pharmaceuticals found in treated wastewaters: study of carbamazepine, clofibric acid, and diclofenac. Ecotoxicol Environ Saf 2003, 55:359-370

13. Zhang W, Zhang M, Lin K, Sun W, Xiong B, Guo M, Cui X, Fu R: Ecotoxicological effect of Carbamazepine on Scenedesmus obliquus and Chlorella pyrenoidosa. Environ Toxicol Pharmacol 2012, 33:344-352.

14. de Lange $H$, Noordoven W, Murk A, Lürling M, Peeters E: Behavioural responses of Gammarus pulex (Crustacea, Amphipoda) to low concentrations of pharmaceuticals. Aquat Toxicol 2006, 78:209-216.

15. Martin-Diaz L, Franzellitti S, Buratti S, Valbonesi P, Capuzzo A, Fabbri E: Effects of environmental concentrations of the antiepilectic drug carbamazepine on biomarkers and CAMP-mediated cell signaling in the mussel Mytilus galloprovincialis. Aquat Toxicol 2009, 94:177-185.

16. Galus M, Kirischian N, Higgins S, Purdy J, Chow J, Rangaranjan S, Li H, Metcalfe C, Wilson JY: Chronic, low concentration exposure to pharmaceuticals impacts multiple organ systems in zebrafish. Aquat Toxicol 2013, 132-133:200-211.

17. Rocco L, Izzo A, Zito G, Peluso C: Genotoxicity in Zebrafish (Danio rerio) Exposed to two Pharmacological Products from an Impacted Italian River. J Environ Analytical Toxicology 2011, 01:103.

18. Zhang Y, Geißen S: Prediction of carbamazepine in sewage treatment plant effluents and its implications for control strategies of pharmaceutical aquatic contamination. Chemosphere 2010, 80:1345-1352.

19. Joss A, Siegrist H, Ternes TA: Are we about to upgrade wastewater treatment for removing organic micropollutants? Water Sci Technol 2008, 57:251-255.

20. Hollender J, Zimmermann SG, Koepke S, Krauss M, McArdell CS, Ort C, Singer H, von Gunten U, Siegrist H: Elimination of organic micropollutants in a municipal wastewater treatment plant upgraded with a full-scale post-ozonation followed by sand filtration. Environ Sci Tech 2009, 43:7862-7869.

21. Petala M, Kokokiris L, Samaras P, Papadopoulos A, Zouboulis A: Toxicological and ecotoxic impact of secondary and tertiary treated sewage effluents. Water Res 2009, 43:5063-5074.

22. Bundschuh M, Zubrod JP, Seitz F, Stang C, Schulz R: Ecotoxicological evaluation of three tertiary wastewater treatment techniques via meta-analysis and feeding bioassays using Gammarus fossarum. J Hazard Mater 2011, 192:772-778 
23. Magdeburg A, Stalter D, Oehlmann J: Whole effluent toxicity assessment at a wastewater treatment plant upgraded with a full-scale post-ozonation using aquatic key species. Chemosphere 2012, 88:1008-1014.

24. Vogna D, Marotta R, Andreozzi R, Napolitano A, d'lschia M: Kinetic and chemical assessment of the $\mathrm{UV} / \mathrm{H}_{2} \mathrm{O}_{2}$ treatment of antiepileptic drug carbamazepine. Chemosphere 2004, 54:497-505.

25. Kosjek T, Andersen HR, Kompare B, Ledin A, Heath E: Fate of carbamazepine during water treatment. Environ Sci Tech 2009, 43:6256-6261.

26. Li Z, Fenet H, Gomez E, Chiron S: Transformation of the antiepileptic drug oxcarbazepine upon different water disinfection processes. Water Res 2011, 45:1587-1596.

27. Donner E, Kosjek T, Qualmann S, Kusk KO, Heath E, Revitt DM, Ledin A Andersen HR: Ecotoxicity of carbamazepine and its UV photolysis transformation products. Sci Total Environ 2013, 443:870-876.

28. Hamer HM, Dodel R, Strzelczyk A, Balzer-Geldsetzer M, Reese J, Schöffski O, Graf W, Schwab S, Knake S, Oertel WH, Rosenow F, Kostev K: Prevalence, utilization, and costs of antiepileptic drugs for epilepsy in Germany-a nationwide population-based study in children and adults. J Neurol 2012, 259:2376-2384.

29. Huber MM, Canonica S, Park G, von Gunten U: Oxidation of pharmaceuticals during ozonation and advanced oxidation processes. Environ Sci Tech 2003, 37:1016-1024.

30. ISO: Water quality - determination of the acute toxicity of waste water to zebrafish eggs (Danio rerio). ISO 2007, 15088:2007.

31. OECD: Draft proposal for a new guideline: fish embryo toxicity (FET) test, 2006. http://www.oecd.org/chemicalsafety/testing/36817070.pdf

32. Lammer E, Carr G, Wendler K, Rawlings J, Belanger S, Braunbeck T: Is the fish embryo toxicity test (FET) with the zebrafish (Danio rerio) a potential alternative for the fish acute toxicity test? Comp Biochem Physiol C Toxicol Pharmacol 2009, 149:196-209.

33. de Esch C, Slieker R, Wolterbeek A, Woutersen R, de Groot D: Zebrafish as potential model for developmental neurotoxicity testing. Neurotoxicol Teratol 2012, 34:545-553

34. Altenburger R, Backhaus T, Boedeker W, Faust M, Scholze M, Grimme LH: Predictability of the toxicity of multiple chemical mixtures to Vibrio fischeri: mixtures composed of similarly acting chemicals. Environ Toxicol Chem 2000, 19:2341.

35. van den Brandhof E, Montforts M: Fish embryo toxicity of carbamazepine, diclofenac and metoprolol. Ecotoxicol Environ Saf 2010, 73:1862-1866.

36. Weigt S, Huebler N, Strecker R, Braunbeck T, Broschard TH: Zebrafish (Danio rerio) embryos as a model for testing proteratogens. Toxicology 2011, 281:25-36.

37. Forcelli PA, Janssen MJ, Vicini S, Gale K: Neonatal exposure to antiepileptic drugs disrupts striatal synaptic development. Ann Neurol 2012, 72:363-372.

38. Muth-Köhne E, Wichmann A, Delov V, Fenske M: The classification of motor neuron defects in the zebrafish embryo toxicity test (ZFET) as an animal alternative approach to assess developmental neurotoxicity. Neurotoxicol Teratol 2012, 34:413-424.

39. Leclercq M, Mathieu O, Gomez E, Casellas C, Fenet H, Hillaire-Buys D: Presence and fate of carbamazepine, oxcarbazepine, and seven of their metabolites at wastewater treatment plants. Arch Environ Contam Toxicol 2009, 56:408-415.

40. Ferrer I, Thurman EM: Identification of a new antidepressant and its glucuronide metabolite in water samples using liquid chromatography/quadrupole time-of-flight mass spectrometry. Anal Chem 2010, 82:8161-8168.

41. D'Ascenzo G, Di Corcia A, Gentili A, Mancini R, Mastropasqua R, Nazzari M, Samperi R: Fate of natural estrogen conjugates in municipal sewage transport and treatment facilities. Sci Total Environ 2003, 302:199-209.

42. Hass U, Dünnbier U, Massmann G, Pekdeger A: Simultaneous determination of psychoactive substances and their metabolites in aqueous matrices by ultrahigh-performance liquid chromatography-tandem mass spectrometry. Anal Methods 2011, 3:902-910.

43. Hass U, Duennbier U, Massmann G: Occurrence and distribution of psychoactive compounds and their metabolites in the urban water cycle of Berlin (Germany). Water Res 2012, 46:6013-6022.

44. Yu JT, Bouwer EJ, Coelhan M: Occurrence and biodegradability studies of selected pharmaceuticals and personal care products in sewage effluent. Agric Water Manag 2006, 86:72-80.

45. Hoshina K, Horiyama S, Matsunaga H, Haginaka J: Molecularly imprinted polymers for simultaneous determination of antiepileptics in river water samples by liquid chromatography-tandem mass spectrometry. J Chromatogr A 2009, 1216:4957-4962.
46. Langford K, Thomas KV: Input of selected human pharmaceutical metabolites into the Norwegian aquatic environment. J Environ Monit 2011, 13:416.

47. Dalton H, Stirling DI, Quayle JR: Co-metabolism [and discussion]. Phil Trans Royal Soc B: Biol Sci 1982, 297:481-496.

48. Dijkman NA, van Vlaardingen $\mathrm{PL}$, Admiraal WA: Biological variation in sensitivity to $\mathrm{N}$-heterocyclic PAHs; effects of acridine on seven species of micro-algae. Environ Pollut 1997, 95:121-126.

49. Shibata M, Hashi S, Nakanishi H, Masuda S, Katsura T, Yano I: Detection of 22 antiepileptic drugs by ultra-performance liquid chromatography coupled with tandem mass spectrometry applicable to routine therapeutic drug monitoring. Biomed Chromatogr 2012, 26:1519-1528.

50. Kim S, Koo T, Ha D, Baek M, Lee S, Shin D, Moon H: Liquid chromatography-tandem mass spectrometry for quantification of lacosamide, an antiepileptic drug, in rat plasma and its application to pharmacokinetic study. Biomed Chromatogr 2011, 26:371-376.

51. Wang C, Gardinali PR: Comparison of multiple API techniques for the simultaneous detection of microconstituents in water by on-line SPE-LC -MS/MS. J Mass Spectrom 2012, 47:1255-1268.

52. Oberacher H, Pavlic M, Libiseller K, Schubert B, Sulyok M, Schuhmacher R, Csaszar E, Köfeler HC: On the inter-instrument and inter-laboratory transferability of a tandem mass spectral reference library: 1 . Results of an Austrian multicenter study. J Mass Spectrom 2009, 44:485-493.

53. Hansen RJ, Samber BJ, Gustafson DL: Rapid and sensitive LC-MS/MS method for determination of felbamate in mouse plasma and tissues and human plasma. J Chromatogr B 2010, 878:3432-3436.

54. Subramanian M, Birnbaum AK, Remmel RP: High-speed simultaneous determination of nine antiepileptic drugs using liquid chromatography-mass spectrometry. Ther Drug Monit 2008, 30:347-356.

55. Bhatt M, Shah S, Shivprakash: Rapid ultraperformance liquid chromatography-tandem mass spectrometry method for quantification of oxcarbazepine and its metabolite in human plasma. Biomed Chromatogr 2011, 25:751-759.

56. La Marca G, Malvagia S, Filippi L, Innocenti M, Rosati A, Falchi M, Pellacani S, Moneti G, Guerrini R: Rapid assay of rufinamide in dried blood spots by a new liquid chromatography-tandem mass spectrometric method. J Pharm Biomed Anal 2011, 54:192-197.

57. US EPA, Office of Water: Methods for measuring the acute toxicity of effluents and receiving waters to freshwater and marine organisms, fifth edition. EPA-821-R-02-012 Washington DC, 2002. http://water.epa.gov/scitech/methods/ cwa/wet/disk2_index.cfm.

\section{doi:10.1186/2190-4715-25-29}

Cite this article as: Hartwig et al: Screening for ecotoxicological effects of antiepileptic drugs in biologically treated waste water originating from an epilepsy ward by Danio rerio embryos. Environmental Sciences Europe 2013 25:29.

\section{Submit your manuscript to a SpringerOpen ${ }^{\odot}$ journal and benefit from:}

- Convenient online submission

- Rigorous peer review

- Immediate publication on acceptance

- Open access: articles freely available online

- High visibility within the field

- Retaining the copyright to your article

Submit your next manuscript at springeropen.com 